\title{
STUDY OF DUCTILE IRON PRODUCTION FOR CASTINGS DESIGNATED FOR EXTREME CONDITIONS
}

\author{
${ }^{1}$ Ladislav SOCHA, ${ }^{1}$ Karel GRYC, ${ }^{1}$ Jana SVIŽELOVÁ, ${ }^{2}$ Miroslav CHMIEL, ${ }^{2}$ Petra FRONKOVÁ, \\ ${ }^{1}$ Kamil KOZA, ${ }^{1}$ Helena KACHLÍŘOVÁ \\ ${ }^{1}$ Institute of Technology and Business in České Budějovice, České Budějovice, Czech Republic, EU, \\ socha@mail.vstecb.cz,gryc@mail.vstecb.cz, svizelova@mail.vstecb.cz, kamil.koza@mail.vstecb.cz, \\ kachlirova@mail.vstecb.cz, \\ ${ }^{2}$ KOVOSVIT MAS Foundry, a.s., Sezimovo Ústí, Czech Republic, EU, \\ chmiel@kovosvit.cz, fronkova@kovosvit.cz
}

https://doi.org/10.37904/metal.2021.4095

\begin{abstract}
This paper studies the possibility of producing ductile iron castings intended for extreme conditions on an industrial scale. The preparation of charge and its melting conditions, modification, primary inoculation and main inoculation were studied within extensive series of experimental melts. In the scope of charge evaluation, especially the ratio of sorel type raw iron to steel charge was studied in order to reduce the raw iron portion while maintaining the castings qualitative requirements. The modifiers FeSiMg621 and FeSiMg731 were evaluated during modification. During primary inoculation the inoculants Inocast100 and SB10 were compared. The inoculation blocks Germalloy were used during main inoculation. The implementation of experimental melts was followed by chemical composition analysis, metallographic evaluation and a study of microstructure and mechanical testing performance of samples. The chemical composition was determined based on optical emission spectrometry and combustion analysis. The metallographic analysis and the microstructure evaluation were made using an optical microscope and image analysis. Testing of mechanical properties was focused on the tensile test, impact test and hardness test. It was proved that the foundry was able to produce the required quality ductile iron made of different combinations of charge materials, modifiers and inoculants. All contemplated combinations of the production technology meet the standard-defined requirements for this type of material.
\end{abstract}

Keywords: Ductile iron, inoculation, modification, performance experiment, metallography

\section{INTRODUCTION}

Cast iron is a material with good mechanical and physical properties. Its relatively low production costs increase an interest in its application in various industries $[1,2,3]$. Cast iron with spheroidal graphite is a modern material with excellent mechanical properties whose tensile strength is even comparable to that of steel. Considering its lower production price, cast iron with spheroidal graphite thus replaces the more expensive steel in some industries [4,5]. Spheroidal graphite is obtained in cast iron by inoculation. The best structure of graphite is achieved using 2-step inoculation [6]. The current trend in cast iron production is to reduce the percentage of raw iron in the charge and to replace this raw iron with the cheaper steel scrap material and thus decrease the production costs [7]. A research has been ongoing at KOVOSVIT MAS Foundry, a.s. focused on studying possible ways of producing castings of cast iron with spheroidal graphite intended for extreme conditions. A SCHAFT 1 type casting was chosen for the tests; this casting is designed for manufacturers of naval manipulators for medium-sized ships. Superior material quality is required for this type of casting. The casting is made of EN-GJS-400-18-LT, i.e. cast iron with spheroidal graphite and a ferrite matrix with a guaranteed value of impact energy at $-20^{\circ} \mathrm{C}[8,9]$. 
The effect of the composition of charge materials and the choice of the modifying and inoculating agent on utility properties of the material were evaluated in the scope of experimental melts. Together with the casting, testing samples - the so-called Y-Blocks - were added to the inlet system of the mould, used to produce test bodies for the metallographic analysis and for the testing of mechanical properties [9, 10,11, 12]. The purpose of the study was to define the most appropriate parameters for the production of castings made of cast iron with spheroidal graphite with a special focus on optimization of the raw iron and steel charge ratio, and the used modifying and inoculating agents.

\section{TECHNOLOGICAL PROCEDURE OF SCHAFT 1 CASTING PRODUCTION}

Based on operating experience, chemical composition of the melt before tapping was proposed at KOVOSVIT MAS Foundry a.s. This composition is shown in Table 1 to give an idea; modification and inoculation will follow. Furthermore, final chemical composition of the melt for the casting was proposed as presented in Table 2.

Table 1 Chemical composition of EN-GJS-400-18-LT before tapping

\begin{tabular}{|c|c|c|c|c|c|c|c|c|}
\hline \multirow{2}{*}{ Range } & \multicolumn{9}{|c|}{ Chemical composition (wt \%) } \\
\cline { 2 - 10 } & $\mathbf{C}$ & Si & Mn & $\mathbf{P}$ & $\mathbf{S}$ & $\mathbf{C u}$ & $\mathbf{M g}$ & $\mathbf{C r}$ \\
\hline Min. & 3.40 & 0.80 & 0.10 & $\times \times \times$ & $\times \times \times$ & $\times \times \times$ & $\times \times \times$ & $\times \times \times$ \\
\hline Max. & 3.50 & 0.90 & 0.15 & 0.040 & 0.015 & 0.05 & $\times \times \times$ & 0.02 \\
\hline
\end{tabular}

Table 2 Proposed final chemical composition of EN-GJS-400-18-LT for the SCHAFT 1 casting

\begin{tabular}{|c|c|c|c|c|c|c|c|c|}
\hline \multirow{2}{*}{ Range } & \multicolumn{9}{|c|}{ Chemical composition (wt \%) } \\
\cline { 2 - 10 } & $\mathbf{C}$ & $\mathbf{S i}$ & $\mathbf{M n}$ & $\mathbf{P}$ & $\mathbf{S}$ & $\mathbf{C u}$ & $\mathbf{M g}$ & $\mathbf{C r}$ \\
\hline Min. & 3.30 & 1.70 & 0.10 & $\times \times \times$ & $\times \times \times$ & $\times \times \times$ & 0.040 & $\times \times \times$ \\
\hline Max. & 3.40 & 1.90 & 0.15 & 0.040 & 0.010 & 0.05 & 0.060 & 0.02 \\
\hline
\end{tabular}

A series of 9 melts was performed in the scope of the operating experiments, testing 3 combinations of charge materials in various ratios. Table 3 provides the composition of the charge for three selected melts identified as TS87, TM11 and TD75.

Table 3 Composition of the charge for melts TS87, TM11 and TD75 for EN-GJS-400-18-LT production

\begin{tabular}{|c|c|c|c|c|c|c|c|}
\hline \multirow{2}{*}{ Melt } & \multicolumn{7}{|c|}{ Composition of charge materials in individual melts (wt \%) } \\
\cline { 2 - 8 } & \multicolumn{2}{|c|}{ Cast iron } & \multicolumn{3}{c|}{ Steel scrap } & Reused material & \multirow{2}{*}{ Total } \\
\cline { 2 - 8 } & Sorel & Pig Nod & Initiation block & Cupol Mn 0.3 \% & Si sheet & Initiation block & \\
\hline TS87 & 61.5 & TS87 & 61.5 & TS87 & 61.5 & TS87 & 61.5 \\
\hline TM11 & 62.0 & $\times \times \times$ & 10.3 & $\times \times \times$ & $\times \times \times$ & 27.7 & 100 \\
\hline TD75 & 38.5 & 20.0 & $\times \times \times$ & 27.7 & 13.8 & $\times \times \times$ & 100 \\
\hline
\end{tabular}

A basic technological production process was prepared for the series of the experimental melts; this process is illustrated in Figure $\mathbf{1}$ and is composed of the following steps:

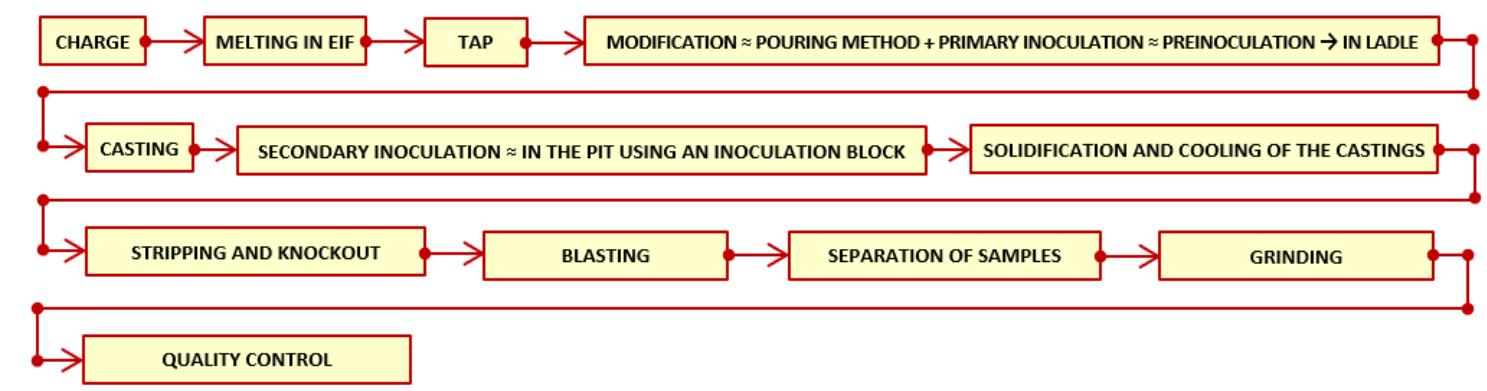

Figure 1 Schematic illustration of the basic technological production process 
$\checkmark \quad$ Charge $\rightarrow$ Preparation of the charge and its selection were controlled individually according to metallurgical and chemical quality of available raw materials with guaranteed chemical composition. The following charge materials were used for the production: raw iron $\times$ steel scrap $\times$ returned production material;

$\checkmark \quad$ Melting $\rightarrow$ is performed as needed according to the amount of the melt corresponding to the number of made castings while 1 or 2 castings were made within a single melting step. A medium-frequency electric induction furnace (EIF) with the capacity of $6 t$ was used for melting;

$\checkmark \quad$ After melting the charge and reaching the sampling temperature $\left(t=1,350^{\circ} \mathrm{C}\right.$ to $\left.1,380^{\circ} \mathrm{C}\right)$, the cinder was thoroughly removed, the bath temperature was measured and a sample was collected for the first test of composition, focused on the following elements: C, Si, Mn, P, S, Cu, Mg and Cr. Subsequently, chemical composition of the melt was corrected. A minimum temperature of the melt was maintained throughout the melting process;

$\checkmark \quad$ Before tapping, chemical composition was verified by the chemical laboratory, focusing on the following elements: $\mathrm{C}, \mathrm{Si}, \mathrm{Mn}, \mathrm{P}, \mathrm{S}, \mathrm{Cu}, \mathrm{Mg}$ and $\mathrm{Cr}$. The purpose of melting was to achieve the required chemical composition and to observe the correct temperature regimen $t_{\max }=1,380^{\circ} \mathrm{C}$;

$\checkmark \quad$ Modification $\rightarrow$ was performed using the pouring method. Before tapping, one piece of raw iron Pig Nod was added to the bath for an improved formation of nuclei. Before modification, the ladle was rinsed with liquid metal to ensure sufficient heating of the brick lining. Subsequently, master alloys were added to the bottom in the order below:

$$
\begin{aligned}
& \circ \text { FeSiMg731 × FeSiMg621 - modifier; } \\
& \circ \text { Inocast100 × SB10 - inoculant; } \\
& \circ \text { LLG cuts - to delay the reaction; }
\end{aligned}
$$

$\checkmark \quad$ Besides modification, primary inoculation - the so-called preinoculation using inoculants - is performed in the ladle at the time of tapping. To give an idea, Figure 2 shows a photograph from melt tapping into the ladle with concurrent modification and primary inoculation;

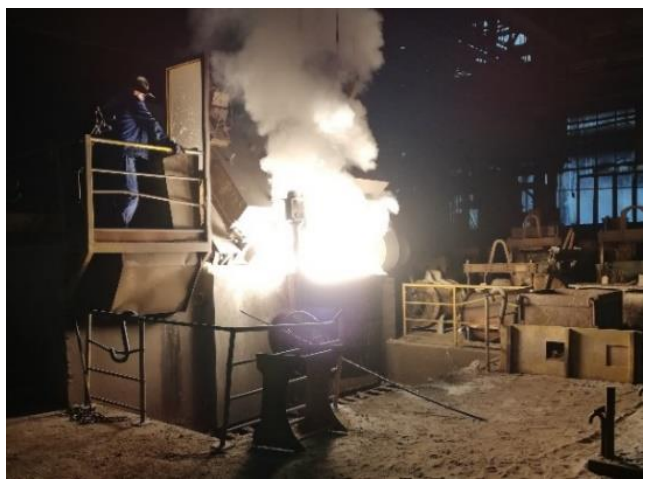

Figure 2 Tapping into the ladle with concurrent modification and primary inoculation

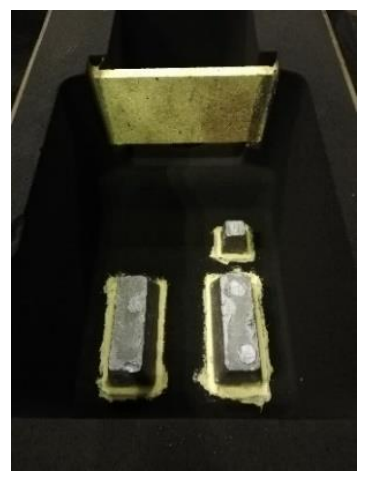

Figure 3 Pit detail at the top part of the mould with prepared inoculation blocks

$\checkmark \quad$ Inoculation $\rightarrow$ is performed in two phases; initially, partially in the course of tapping into the ladle, the so-called preinoculation, and subsequently, the so-called main inoculation, performed in the pit using inoculation blocks in the course of making the casting. Figure 3 shows the detail of the inoculation pit with prepared inoculation blocks; Inoculants Inocast100 $\times$ SB10 are used to optimize the structure of the cast iron with spheroidal graphite. The selection of the type and amount of the inoculant was performed based on the amount of liquid metal and the casting duration;

$\checkmark \quad$ Table 4 shows the modifiers and inoculants and their amounts used in the selected melts; 
Table 4 Overview of modifiers and inoculants used in the melts during EN-GJS-400-18-LT production

\begin{tabular}{|c|c|c|c|c|c|}
\hline \multirow{2}{*}{ Melt } & \multicolumn{2}{|c|}{ Modifier } & \multicolumn{2}{c|}{ Pre-inoculation } & Main inoculation \\
\cline { 2 - 6 } & Name & Amount (\%) & Name & Amount (\%) & Germalloy (block) \\
\hline TS87 & FeSiMg621 & 1.95 & SB10 & 0.1 & $2 x$ P2 + P300 \\
\hline TM11 & FeSiMg731 & 1.80 & Inocast100 & 0.1 & P3 + P2 + P300 \\
\hline TD75 & FeSiMg731 & 1.80 & SB10 & 0.1 & $2 x$ P2 + P300 \\
\hline
\end{tabular}

$\checkmark \quad$ Casting, finishing operations and output control $\rightarrow$ before casting, the cinder has to be carefully removed. Casting and cooling are followed by stripping of the mould, knockout of the casting, blasting and deposition in the storage area. Figure 4 shows a photograph of the casting process and Figure 5 shows the photograph of a casting after its removal from the mould and blasting;

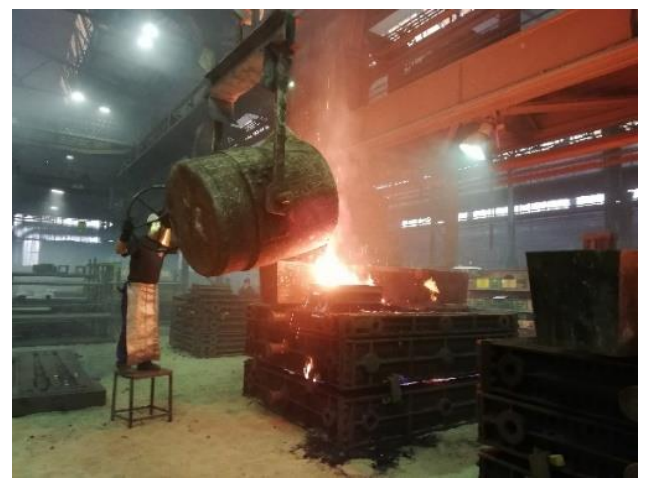

Figure 4 Melt casting into the mould over a pit with inoculation blocks

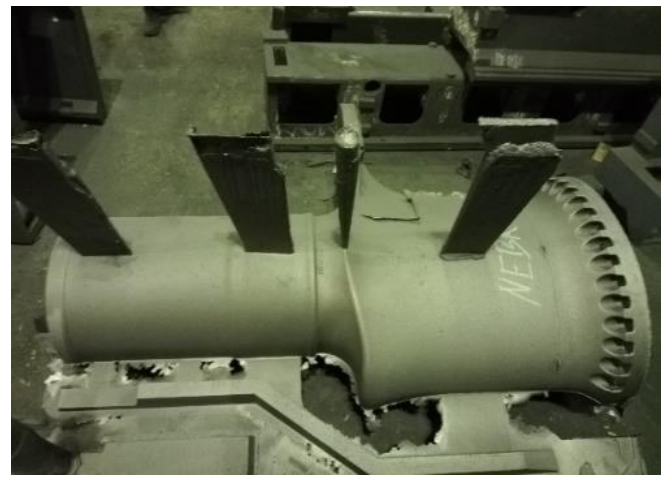

Figure 5 SCHAFT 1 casting after removal from the mould and blasting

$\checkmark \quad$ Testing Y-Blocks are added to every casting in the mould; these blocks are then used to make testing bodies for chemical and metallurgical analysis and tests of mechanical properties. Subsequently, control tasks of the casting follow, including visual inspection and inspection using ultrasound. Furthermore, tests of mechanical properties are performed - tension and bending impact tests.

\section{ANALYSIS OF SAMPLES FROM EXPERIMENTAL MELTS}

Melt samples were taken from selected points with concurrent temperature measurement in the course of the above mentioned series of experimental melts. Additionally, Y-Blocks placed in the inlet system were cast at the same time. The collected samples were identified and gradually analysed; the specifications of individual analyses are described below:

$\checkmark \quad$ Chemical composition analysis $\rightarrow$ the analysis was performed using optical emission spectroscopy (OES) with excitation using a high-energy spark discharge, using the Q4 TASMAN device. The exact content of $C$ and $S$ was determined using combustion analysis in the LECO CS230 high-frequency furnace, in a flow of oxygen. Furthermore, the measured values were used to calculate the carbon equivalent $C E$ and the saturation degree (eutecticity) $S_{c}$;

$\checkmark \quad$ Metallographic analysis was focused on microscopic evaluation to determine the achieved structure of EN-GJS-400-18-LT. Samples made of the Y-Block testing bodies were used to perform metallographic analyses using a light microscope and a line electronic microscope and a scanning electron microscope (SEM) with the EDX mode. Graphite assessment was performed according to the following standards: ČSN EN ISO 945-1 [10] $\rightarrow$ focused on graphite classification based on visual analysis, ASTM A247 [11] $\rightarrow$ evaluation of graphite nodularity, and ČSN 42 0461 [12] $\rightarrow$ evaluation of cast iron matrix. It was possible to obtain a complex idea of EN-GJS-400-18-LT structure in this way; 
$\checkmark \quad$ Mechanical properties $\rightarrow$ were focused on tension and bending impact tests (Charpy hammer) and hardness tests. The above mentioned devices can be used to perform the following analyses: tensile strength $(R m)$, proof strength $\left(R_{p 0.2}\right)$, elongation $\left(A_{5}\right)$, Brinell hardness $(H B)$ a impact strength $\left(K V_{2}\right)$ at room temperature $23^{\circ} \mathrm{C}$ and at low temperatures $-20^{\circ} \mathrm{C}$ or $-40^{\circ} \mathrm{C}$.

\section{RESULTS AND DISCUSSION}

After the experimental melts, evaluation was performed to determine the mechanical properties, as well as metallographic evaluation and evaluation of the microstructure $[9,10,11,12]$. The results are summarized in the so-called metallographic cards that provide an idea of the mechanical properties and of the resulting structure of EN-GJS-400-18-LT used to cast a SCHAFT 1 type casting. An example of such a card for TM11 melt is provided in Tables 5 to Table 8 and in Figure 6.

Table 5 Characteristics of modification and inoculation $\rightarrow$ melt TM11

\begin{tabular}{|c|c|c|}
\hline \multicolumn{2}{|c|}{ Modification and pre-inoculation $\rightarrow$ pouring method } & Main inoculation $\rightarrow$ inlet well \\
\hline Modifier: name $\rightarrow$ amount (wt \%) & Inoculant: name $\rightarrow$ amount (wt \%) & Inoculant: name $\rightarrow$ amount \\
\hline FeSiMg731 $\rightarrow 1.8 \%$ & Inocast100 $\rightarrow 0.1 \%$ & Germalloy $\rightarrow 1 \times$ P3+P2+P300 \\
\hline
\end{tabular}

Table 6 Chemical composition $\rightarrow$ melt TM11

\begin{tabular}{|c|c|c|c|c|c|c|c|c|c|}
\hline \multicolumn{9}{|c|}{ Chemical composition (wt \%) } & \multicolumn{3}{c|}{ Parameters } \\
\hline $\mathbf{C}$ & $\mathbf{S i}$ & $\mathbf{M n}$ & $\mathbf{P}$ & $\mathbf{S}$ & $\mathbf{C u}$ & $\mathbf{C r}$ & $\mathbf{M g}$ & $\mathbf{C E}$ & $\mathbf{S}_{\mathbf{c}}$ \\
\hline 3.67 & 1.77 & 0.11 & 0.034 & 0.008 & 0.01 & 0.01 & 0.076 & 4.21 & 0.99 \\
\hline
\end{tabular}

Table 7 Achieved mechanical properties $\rightarrow$ melt TM1

\begin{tabular}{|c|c|c|c|c|}
\hline Property & \multicolumn{2}{|c|}{ Value as per ČSN EN 1563} & \multicolumn{2}{|c|}{ Measured value } \\
\hline Tensile strength $\mathrm{R}_{\mathrm{m}}(\mathrm{MPa})$ & \multicolumn{2}{|c|}{ Min. $360 \mathrm{MPa}$} & \multicolumn{2}{|c|}{$376 \mathrm{MPa}$} \\
\hline $0.2 \%$ Proof strength $\mathrm{R}_{\mathrm{p} 02}(\mathrm{MPa})$ & \multicolumn{2}{|c|}{ Min. $220 \mathrm{MPa}$} & \multicolumn{2}{|c|}{$282 \mathrm{MPa}$} \\
\hline Elongation after fracture $\mathrm{A}_{5}(\%)$ & \multicolumn{2}{|c|}{ Min. $12 \%$} & \multicolumn{2}{|c|}{$24.3 \%$} \\
\hline Brinell hardness (HB) & \multicolumn{2}{|c|}{ Min. $130 H B$} & \multicolumn{2}{|c|}{$130 \mathrm{HB}$} \\
\hline \multirow{9}{*}{$\begin{array}{l}\text { Minimum impact energy } \\
\text { value } \mathrm{KV}_{2}(\mathrm{~J})\end{array}$} & \multicolumn{4}{|c|}{ Temperature $(+23 \pm 2)^{\circ} \mathrm{C}$} \\
\hline & Mean value (3 tests) & Individual value & Mean value (3 tests) & Individual value \\
\hline & $x \times x$ & $x \times x$ & $15 \mathrm{~J}$ & $16 / 15 / 15 \mathrm{~J}$ \\
\hline & \multicolumn{4}{|c|}{ Low temperature $(-20 \pm 2)^{\circ} \mathrm{C}$} \\
\hline & Mean value (3 tests) & Individual value & Mean value (3 tests) & Individual value \\
\hline & $10 \mathrm{~J}$ & $7 \mathrm{~J}$ & $17 \mathrm{~J}$ & $17 / 17 / 17 \mathrm{~J}$ \\
\hline & \multicolumn{4}{|c|}{ Low temperature $(-40 \pm 2)^{\circ} \mathrm{C}$} \\
\hline & Mean value (3 tests) & Individual value & Mean value (3 tests) & Individual value \\
\hline & $x \times x$ & $x \times x$ & $15 \mathrm{~J}$ & $14 / 15 / 15 \mathrm{~J}$ \\
\hline
\end{tabular}

Table 8 Metallographic structure evaluation $\rightarrow$ melt TM11

\begin{tabular}{|l|l|l|}
\hline \multicolumn{1}{|c|}{ ČSN EN ISO 945-1 } & \multicolumn{1}{c|}{ ASTM A 247 } & \multicolumn{1}{c|}{ ČSN 420461 } \\
\hline Graphite form: $71 \% \mathrm{VI}+26 \% \mathrm{~V}+3 \%$ III & Nodularity: $71 \%$ & Perlite content P1: P0 (up to $2 \%)$ \\
\hline Graphite size range: $\underline{6} / 7$ & Particles per $\mathrm{mm}^{2}: 256$ & $\times \times \times$ \\
\hline Dimensions of graphite particle: $<15-30 \mu \mathrm{m}$ & $\times \times \times$ & $\times \times \times$ \\
\hline
\end{tabular}




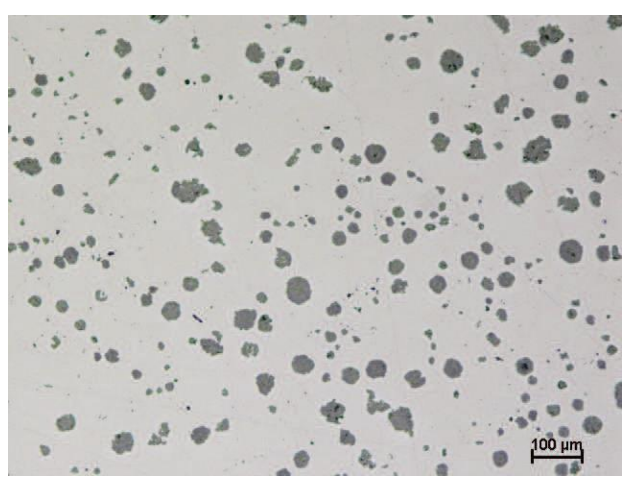

a) Picture by ČSN EN ISO 945-1

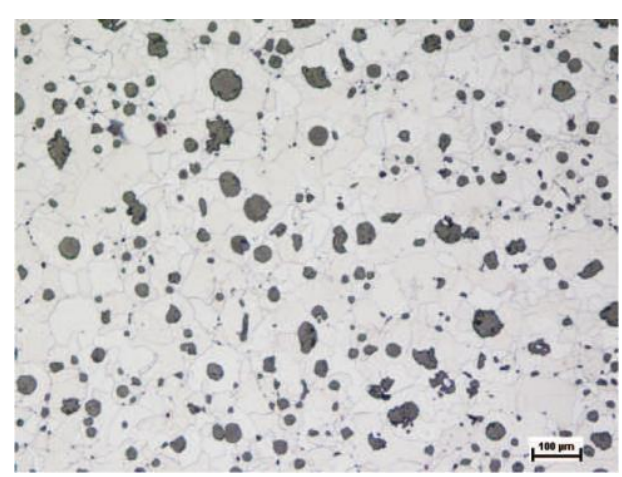

b) Picture by ČSN 420461

Figure 6 Illustration of cast iron with spheroidal graphite $\rightarrow$ melt TM11

Evaluation of results of the experimental melts $\rightarrow$ based on a complex assessment of the so-called metallographic cards of EN-GJS-400-18-LT for SCHAFT 1 castings. Table 9 gives chemical composition of the melt after modification and preinoculation and the carbon equivalent $\mathrm{CE}$ and the saturation degree (eutecticity) Sc for melts TS87, TM11 and TD75.

Table 9 Achieved chemical composition of the melt after modification and preinoculation for melts TS87, TM11 and TD75

\begin{tabular}{|c|c|c|c|c|c|c|c|c|c|c|}
\hline \multirow{2}{*}{ Melt } & \multicolumn{9}{|c|}{ Chemical composition (wt \%) } & \multicolumn{2}{c|}{ Parameters } \\
\cline { 2 - 12 } & $\mathbf{C}$ & $\mathbf{S i}$ & $\mathbf{M n}$ & $\mathbf{P}$ & $\mathbf{S}$ & $\mathbf{C u}$ & $\mathbf{M g}$ & $\mathbf{C r}$ & $\mathbf{C E}$ & $\mathbf{S c}$ \\
\hline TS87 & 3.31 & 1.80 & 0.16 & 0.037 & 0.009 & 0.02 & 0.066 & 0.02 & 3.86 & 0.90 \\
\hline TM11 & 3.67 & 1.77 & 0.11 & 0.034 & 0.008 & 0.01 & 0.076 & 0.01 & 4.21 & 0.99 \\
\hline TD75 & 3.32 & 1.74 & 0.11 & 0.049 & 0.008 & 0.01 & 0.053 & 0.02 & 3.86 & 0.90 \\
\hline
\end{tabular}

The achieved chemical composition shown in Table 9 corresponds to the chemical composition proposed in Table 3 except several deviations up to a few tenths of a percentage for C, Mn, P and Mg. Nevertheless, these minor deviations have no effect on material quality as discussed below. The charge preparation process and charge melting have been thus managed well.

Table 10 gives a summary of mechanical properties determined for samples from melts TS87, TM11 and TD75. The following can be stated based on the results:

$\checkmark \quad$ As regards tensile tests, the highest tensile strength $R_{m}$ was achieved for melt TS87, namely $427 \mathrm{MPa}$. The mean value of tensile strength $R_{m}$ was achieved for melt TD75, namely $413 \mathrm{MPa}$. The lowest tensile strength $R_{m}$ was achieved for melt TM11, namely $376 \mathrm{MPa}$;

$\checkmark \quad$ The highest proof strength $R_{p 0.2}$ was achieved for melt TM11, namely $282 \mathrm{MPa}$. The mean value of proof strength $R_{p 0.2}$ was achieved for melt TD75, namely $251 \mathrm{MPa}$. The lowest proof strength $R_{p 0.2}$ was achieved for melt TS87, namely $249 \mathrm{MPa}$;

$\checkmark \quad$ The highest elongation $A_{5}$ was achieved for melt TM11, namely 24.3\%. The mean elongation $A_{5}$ was achieved for melt TD75, namely $21.4 \%$. The lowest elongation $A_{5}$ was achieved for melt TS87, namely 17\%;

$\checkmark \quad$ As regards the hardness test, the value of $134 \mathrm{HB}$ was achieved for melt TS87, $131 \mathrm{HB}$ for melt TD75 and $130 \mathrm{HB}$ for melt TM11;

$\checkmark \quad$ As regards bending impact energy tests at $20^{\circ} \mathrm{C}$, the mean value of impact energy $K V_{2}$ of $15 \mathrm{~J}$ was achieved for melts TS87 and TM11, and $16 \mathrm{~J}$ for melt TD75. At $-20^{\circ} \mathrm{C}$, the mean value of impact energy $K V_{2}$ of $15 \mathrm{~J}$ was achieved for melt TS87, $17 \mathrm{~J}$ for melt TM11, and $13 \mathrm{~J}$ for melt TD75. At $-40^{\circ} \mathrm{C}$, the mean value of impact energy $K V_{2}$ of $14 \mathrm{~J}$ was achieved for melt TS87, $15 \mathrm{~J}$ for melt TM11, and $14 \mathrm{~J}$ for melt TD75. There are no major differences between impact energy values at $-20^{\circ} \mathrm{C}$ and $23^{\circ} \mathrm{C}$. The impact 
energy values slightly decreased at $-40^{\circ} \mathrm{C}$; however, this change is not significant. Thus the castings are suitable for use even at such low temperatures.

Table 10 Overview of mechanical properties of samples from experimental melts TS87, TM11 and TD75

\begin{tabular}{|c|c|c|c|c|c|c|c|c|c|c|}
\hline \multirow{2}{*}{ Melt } & \multirow{2}{*}{$\begin{array}{c}R_{m} \\
(\mathrm{MPa})\end{array}$} & \multirow{2}{*}{$\begin{array}{c}\mathbf{R}_{\mathrm{p} 0,2} \\
(\mathrm{MPa})\end{array}$} & \multirow{2}{*}{$\begin{array}{l}A_{5} \\
(\%)\end{array}$} & \multirow{2}{*}{$\begin{array}{l}\text { Herchess } \\
\text { (HB) }\end{array}$} & \multicolumn{2}{|c|}{$\mathrm{KV}_{2}\left(23^{\circ} \mathrm{C}\right)(\mathrm{J})$} & \multicolumn{2}{|c|}{$\mathrm{KV}_{2}\left(-20^{\circ} \mathrm{C}\right)(\mathrm{J})$} & \multicolumn{2}{|c|}{$\mathrm{KV}_{2}\left(-40^{\circ} \mathrm{C}\right)(\mathrm{J})$} \\
\hline & & & & & Mean & Individual & Mean & Individual & Mean & Individual \\
\hline TS87 & 427 & 249 & 17.0 & 134 & 15 & $15 / 16 / 15$ & 15 & $16 / 15 / 15$ & 14 & $13 / 14 / 14$ \\
\hline TM11 & 376 & 282 & 24.3 & 130 & 15 & 16/15/15 & 17 & 17/17/17 & 15 & 14/15/15 \\
\hline TD75 & 413 & 251 & 21.4 & 131 & 16 & 16/16/15 & 13 & $14 / 13 / 13$ & 14 & $15 / 12 / 14$ \\
\hline
\end{tabular}

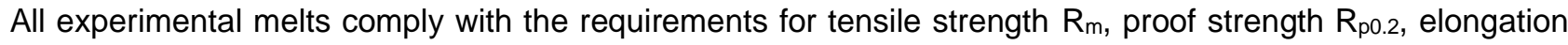
$A_{5}$, Brinell hardness HB and impact energy $\mathrm{KV}_{2}$ as per ČSN EN 1563 for EN-GJS-400-18-LT with the standard wall thickness of $60<\mathrm{t} \leq 200 \mathrm{~mm}$.

It should be mentioned that ČSN EN 1563 [9] determines the minimum impact energy value $\mathrm{KV}_{2}$ for EN-GJS$400-18-\mathrm{LT}$ only for the temperature of $-20^{\circ} \mathrm{C}$; given the complexity of evaluation of individual melts, impact energy was determined also at $23^{\circ} \mathrm{C}$ and $-40^{\circ} \mathrm{C}$. Table 11 provides a summary of parameters describing the achieved structure of the cast iron and graphite.

Table 11 Summary of metallographic evaluation of experimental melts TS87, TM11 and TD75

\begin{tabular}{|c|c|c|c|c|c|c|}
\hline Melt & $\begin{array}{c}\text { Particles } \\
\text { per } \mathbf{m m}^{2}\end{array}$ & $\begin{array}{c}\text { Dimensions of } \\
\text { graphite particle }\end{array}$ & $\begin{array}{c}\text { Graphite } \\
\text { size range }\end{array}$ & Nodularity & $\begin{array}{c}\text { Graphite } \\
\text { form }\end{array}$ & $\begin{array}{c}\text { Perlite } \\
\text { content P1 }\end{array}$ \\
\hline TS87 & 336 & $15-60 \mu \mathrm{m}$ & $6 / \underline{7}$ & $89 \%$ & $89 \% \mathrm{VI}+11 \% \mathrm{~V}$ & $\mathrm{P} 0$ (up to $2 \%)$ \\
\hline TM11 & 256 & $<15-30 \mu \mathrm{m}$ & $\underline{6} / 7$ & $71 \%$ & $71 \% \mathrm{VI}+26 \% \mathrm{~V}+3 \%$ III & $\mathrm{P} 0$ (up to $2 \%)$ \\
\hline TD75 & 298 & $15-60 \mu \mathrm{m}$ & $6 / \underline{7}$ & $93 \%$ & $93 \% \mathrm{VI}+7 \% \mathrm{~V}$ & $\mathrm{P} 0$ (up to $2 \%)$ \\
\hline
\end{tabular}

As follows from Table 11, the highest number of graphite particles per $\mathrm{mm}^{2}$ was achieved in melt TS87, namely 336 with nodularity $89 \%$ and graphite particle sizes $15-60 \mu \mathrm{m}$, which corresponds to the size range of 6/7 . For melt TD75, 298 graphite particles per $\mathrm{mm}^{2}$ were obtained with nodularity $93 \%$ and graphite particle sizes $15-60 \mu \mathrm{m}$, which corresponds to the size range of $6 / \underline{7}$. For melt TM11, 256 graphite particles per $\mathrm{mm}^{2}$ were obtained with nodularity $71 \%$ and graphite particle sizes $<15-30 \mu \mathrm{m}$, which corresponds to the size range of $\underline{6} / 7$.

Thus, it can be noted that all melts comply with the requirements for the microstructure of EN-GJS-400-18-LT. They contain mostly the required type VI graphite, type $\mathrm{V}$ graphite to a limited extent, and also type III graphite only in sporadic cases and up to low percentage values as per ČSN EN ISO 945 [10]. The perlite content is up to $2 \%$. Furthermore, it can be stated that graphite particle sizes decrease with an increasing number of these particles.

\section{CONCLUSION}

The paper describes the study of the production of cast iron with spheroidal graphite for castings intended for extreme conditions. Operating tests were implemented for this purpose at KOVOSVIT MAS Foundry a.s., focused on verifying the possibility of producing castings of EN-GJS-400-18-LT designed for manufacturers of naval manipulators for medium-sized ships. The following conclusions were drawn based on the test results:

$\checkmark \quad$ A melt of the required chemical composition can be obtained at the foundry using various combinations of charge materials, modifiers and inoculants;

$\checkmark \quad$ Modification using the pouring method was used for the experimental melts and inoculation was performed in two phases. First, primary inoculation was done at the time of tapping into the ladle - the 
so-called preinoculation; subsequently, the so-called main inoculation was done, implemented in the pit using inoculation blocks;

$\checkmark \quad$ All studied combinations of the charge materials, modifiers and inoculants complied with the parameters determined by ČSN EN 1563 for EN-GJS-400-18-LT;

$\checkmark \quad$ As found based on metallographic study and structure analysis, cast iron with spheroidal graphite was obtained, containing a high number of graphite particles with high nodularity. The structure is mostly ferritic with less than $2 \%$ of perlite;

$\checkmark \quad$ Based on the results herein, it can be stated that KOVOSVIT MAS Foundry, a.s. is capable of producing high-quality cast iron with spheroidal graphite intended for extreme conditions;

$\checkmark \quad$ For the future, the production process can be enhanced using the modern technology of a filled profile in a twin-core arrangement for inoculation and modification where one core will contain the modifier and the other one will contain the inoculant.

\section{ACKNOWLEDGEMENTS}

The paper was prepared under the support of the Czech Ministry of Industry and Trade within the scope of the TRIO programme, as part of projects Reg. No. FV40036 "Research and development of complex technology of castings production from high-quality ductile iron castings".

\section{REFERENCES}

[1] HOLGER, G., STARKE, P., KERSCHER, E., EIFLER D. Fatigue behaviour and lifetime calculation of the cast irons EN-GJL-250, EN-GJS-600 and EN-GJV-400. Procedia Engineering. 2010, vol. 2, pp. 1087-1094.

[2] HAMPL, J., VÁLEK, T., LICHÝ, P., ELBEL, T. Control of the metallurgical processing of ICDP cast irons. Materiali in Tehnologije. 2014, vol. 48, no. 5, pp. 685-688.

[3] VASKOVA, I., CONEV, M., HRUBOVCAKOVA, M. The influence of using different types of risers or chills on shrinkage production for different wall thickness for material EN-GJS-400-18LT. Archives of Foundry Engineering. 2017, vol. 17, iss. 2, pp. 131-136. ISSN 2299-2944.

[4] LIU, JH., YAN, JS., ZHAO, XB., FU, BG., XUE, HT., ZHANG GX., YANG, PH. Precipitation and evolution of nodular graphite during solidification process of ductile iron. China Foundry. 2020, vol. 17, pp. 260-271.

[5] ROUČKA, J. Cast iron metallurgy. Brno: PC-DIR, 1998.

[6] MOURAD, M.M., EL-HADAD, S., IBRAHIM, M.M., NOFAL, A.A. Effect of Processing Parameters on the Mechanical Properties of Heavy Section Ductile Iron. Journal of Metallurgy. 2015, vol. 2015, pp. 1-11.

[7] VAŠKO, A. Fatigue properties of nodular cast iron at low frequency cyclic loading. Archives of Metallurgy and Materials. 2017, vol. 62, pp. 2205-2210.

[8] ČANŽAR, P., TONKOVIĆ, Z., KODVANJ, J. Microstructure influence on fatigue behaviour of nodular cast iron. Materials Science and Engineering A. 2012, vol. 556, pp. 88-99.

[9] ČSN EN 1563. Foundry - Cast iron with spheroidal graphite. Praha: Czech Office for Standards, Metrology and Testing, 2019, p. 52.

[10] ČSN EN ISO 945-1. Microstructure of cast irons - Part 1: Graphite classification by visual analysis. Praha: Czech Office for Standards, Metrology and Testing, 2020, p. 68.

[11] ASTM A247-19. Standard test method for evaluating the microstructure of graphite in iron castings, ASTM International, 2019, p. 26.

[12] ČSN 42 0461. Evaluation of metallographic structure of cast irons, Praha: Czech Office for Standards, Metrology and Testing, 1975, p. 36. 